\title{
TWO PIECES OF LECTURE APPARATUS FOR LANTERN DEMONSTRATION.
}

By Will C. Baker,

School of Mining, Queen's University, Kingston, Ont.

The following notes contain descriptions of the adaption of two familiar experiments for use in the projection lantern.

\section{PITH BALLS FOR THE LANTERN.}

Experiments with pith balls require a lantern to magnify the small motions so as to make them visible to a class, even in well lighted class rooms. The chief trouble in using pith balls in a lantern is that the charged balls fly to the condenser and other parts of the lantern, thereby not only getting out of focus but losing their charges as well. These troubles disappear with the use of a double suspension for the balls and a guide strip to keep their displacements parallel to the condenser. The device will be most readily understood by reference to the sketch (Figure I.) $A$ is the guide strip, screwed to the base board $B$ $30 x i 0 \mathrm{~cm}$. $)^{1} C$ is a fixed up-

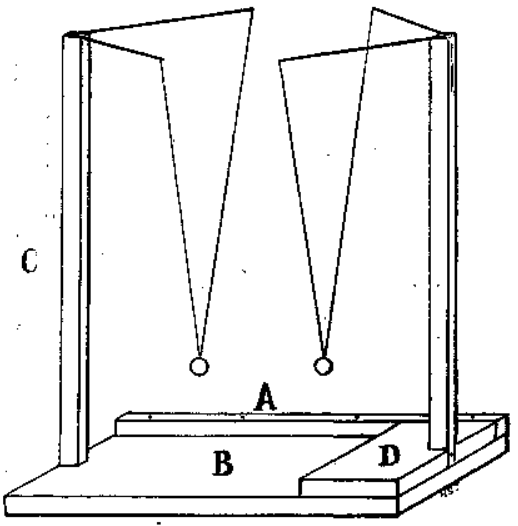

Fig. 1. right $(50 \mathrm{~cm}$. high) carrying two fairly stout copper wires ( $5 \mathrm{~cm}$. long and inclined to one another at $60^{\circ}$ ). From the outer ends of these wires is supported by silk fibres ${ }^{2}(35 \mathrm{~cm}$. long) one of the gilt pith balls. The second pith ball is similarly supported from an upright in the sliding piece $D$; the wire ends of which are a little farther apart than those of the fixed support. ${ }^{3}$. By bending the copper wire arms, the balls are readily adjusted so that they hang at the same height. and so that both swing in the same plane parallel to the condenser.

With such a piece of apparatus all the usual pith ball experiments may be performed in the lantern with comfort. When only

\footnotetext{
1 These dimensions refer to the apparatus in this University, for a lantern with an 11 cm. condenser:

2 By untwisting a meter of white silk twist, one may easily draw long silk fibres from the untwisted strands.

${ }^{3}$ This enables the supports to be slid past one another when desired.
} 
one ball is required the movable support may be lifted to one side. When two balls are used the guide strip enables the lecturer to keep them both in focus while moving them together or apart.

II. A LANTERN DEMONSTRATION OF THE LAWS OF ELECTROSTATIC INDUCTION.

The device described below has given much satisfaction in recent elementary lectures in this university. $A$ and $B$ (Figures 2 and 3 ) are gold leaf electroscopes made of two strips of thin

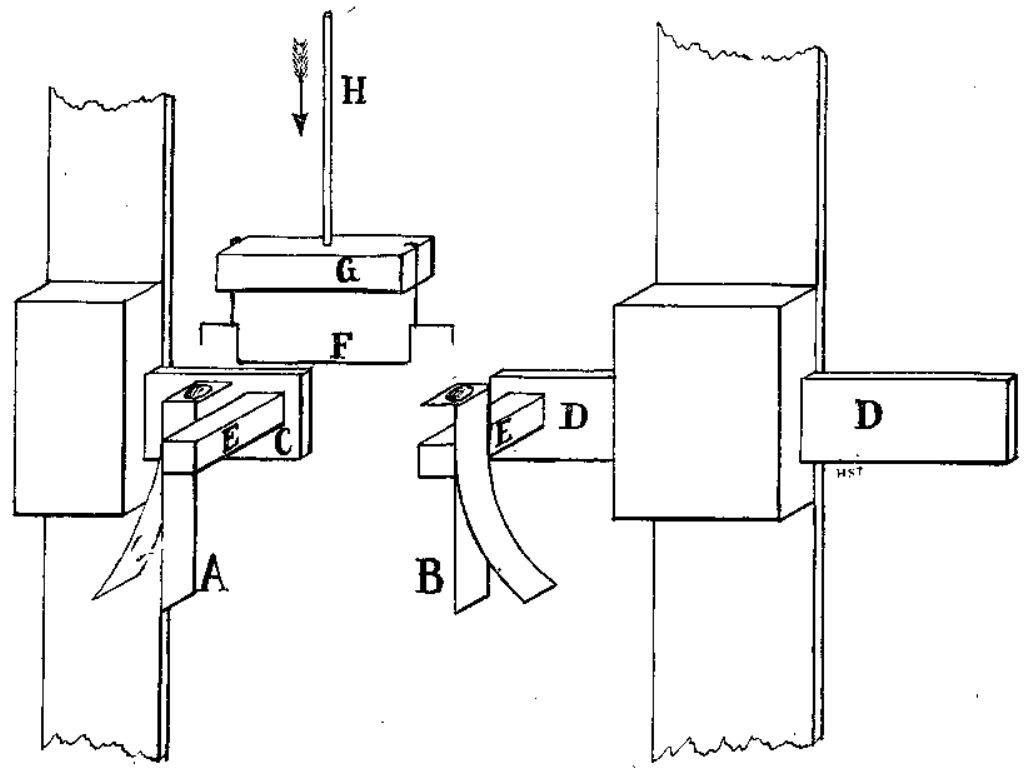

Fig. 2.

brass $\left(4 \frac{1}{2} \times x^{\mathrm{T}} / 2 \mathrm{~cm}.\right)$; the top half centimeter of each is bent at right angles and these parts are slightly cupped to receive the ends of the connecting wire, to be described later. The brass strips are attached to the glass arms ${ }^{4} C$ and $D$ by pieces of seai. ing wax (say $0.7 \times 0.7 \times 3 \mathrm{~cm})$. The $\operatorname{arm} C(2 \times 8 \times 0.2 \mathrm{~cm}$.) is attached by a tight clamp to the inside of the wooden case (see figures 2 and 3$)$. The arm $D(2 \times 15 \times 0: 5 \mathrm{~cm}$.), one end of which projects outside the case, is held by a loose clamp so that it may be pushed forward until the two electroscopes are in contact. $F$ is a wire (bent so as to hang in a stable position)

4the glass is to provide a transparent support. The sealing wax provides the insula-
tion. 
that may connect the electroscopes. This wire is suspended by silk threads from the piece of sealing wax, $G$, which in turn is cemented to the wire $H$. $H$ projects through the bush on top of the box and enables the lecturer to raise or lower $F$ at will. The set screw enables $H$ to be clamped at any height. An earth-connected strip of tin $K$ is also added to increase the charges induced on $A$ and $B$.

The whole apparatus is enclosed in a wooden box $(20 \times 30 \times 8$

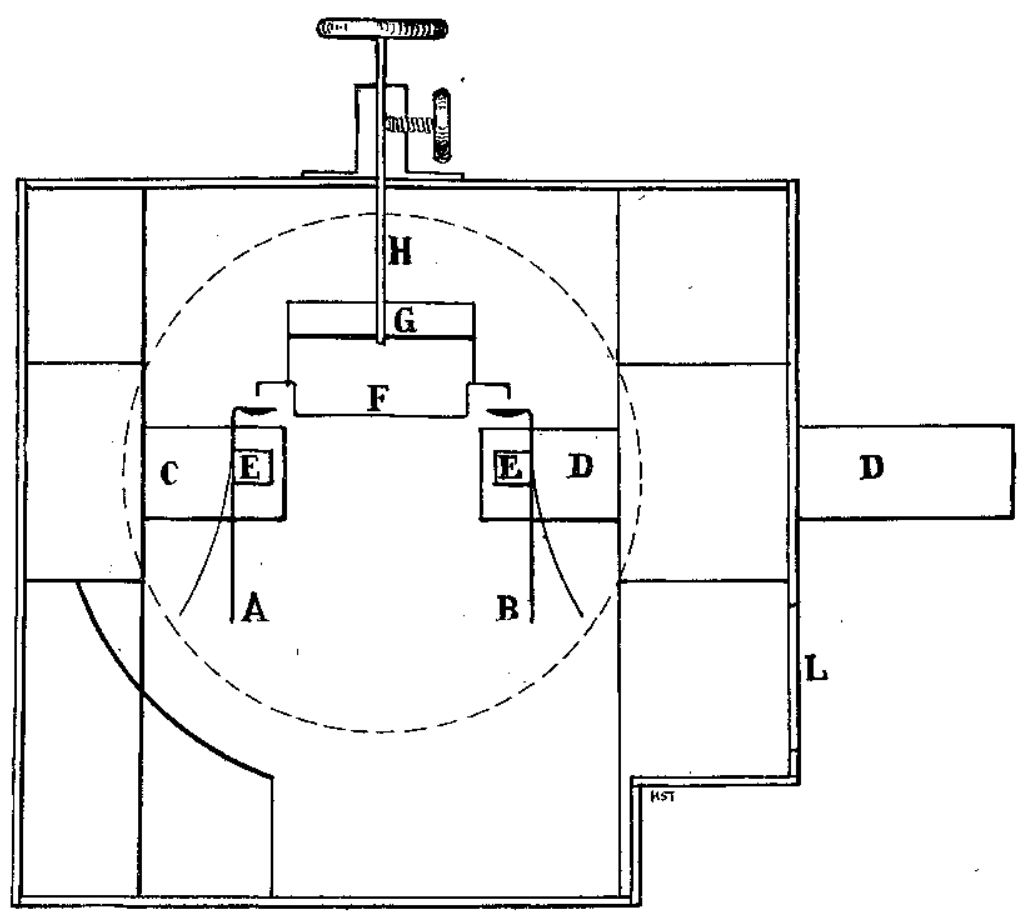

Fig. 3.

cm.) having the two largest sides partly of glass. A notch in one corner (figure 3 ) is necessitated by the construction of the writer's lantern. An opening ( $5 \times 7 \mathrm{~cm}$.) in left at $L$ (figure 3 ) for the introduction of the charged body that is to cause the induction. The dotted circle (figure 3 ) shows the size and position of the lantern condenser. The gold leaves are most conveniently attached by short strips of gummed paper, as the straight edge of the paper catuses the gold foil to bend along a line that makes a good hinge. 
The demonstration is made as follows: After drawing the attention of the class to the electroscopes and the connecting wire, the latter is lowered until it puts $A$ and $B$ into electrical connection. A rubbed ebonite $\operatorname{rod}$ is introduced through $L$ until the excited part is just below $B$. Care must be taken that no spark passes. Both electroscopes deflect. Still holding the rod under $B$, the connecting wire $F$ is lifted, isolating the induced charges. If now the excited rod be removed the electroscope remains equally deflected and when the rod is brought down outside the case, so as to be above the electroscopes and equidistant from them, the leaf of $B$ falls, while that of $A$ rises; showing negative electricity on the latter and positive on the former. ${ }^{5}$ Thus the law of the sign of the induced charges is shown. Next if, by means of the projecting arm $D$, the electroscope $B$ be pushed forward until it touches $A$ the two charges are found to neutralize one another, proving them not only of opposite sign but also of the same magnitude.

Of course this latter fact may be obtained by simply showing that both leaves rise when the excited rod is held $\operatorname{under} B$ and both collapse when the rod is removed, ( $F$ being down ditring the entire operation and the system being initially unchanged). Experience shows that the procedure first described gives the class a livelies sense of the essential points than the latter, simply because in the former their attention is directed to one point at a time.

It is the practice of the writer to give the second demonstration only after the full law is understood by the class.

The production of caoutchouc by chemical means has, indeed, virtually been accomplished in its formation from the isoprene. The exact nature of this change has still to be determined. When this has been done it will remain only to cheapen the cost of production to make the manufacture of synthetic rubber a purely practical problem. Still, the great extension of rubber planting which is now taking place is warranted by the present demand for the material. It has also to be renembered that the actual cost of producing raw rubber will probably be reduced, and the market price of rubber may eventually be so considerably lowered that, as with quinine, the synthetic production could not be profitably carried on. That is a question which involves many factors at present unknown, and only time can decide.-Scientific A meriean supplement.

\footnotetext{
5 It must be shown first of course that when a charged rod is brought over a charged electroscope: the leaf rises when the charges are similar but falls when the charges are dissimilar. This may be taken as an experimental fact and the explanation left until the law of induction has been established.
} 